$$
\begin{aligned}
& \text { روبين يإيمئ }
\end{aligned}
$$

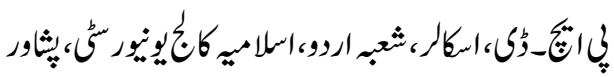

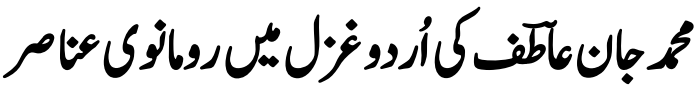

\section{Rubina Yasmin}

Ph.D Scholar, Department of Urdu, Islamia College University, Peshwar.

\section{Romantic Elements in Urdu Ghazal of Muhammad Jaan Atif}

Romanticism is the essence of human nature and fundamental attribute of human society. Human life breaths in the lap of romanticism. Love and passion are the undeniable and unavoidable features of human interactions and poetic expressions. The reflection of these attributes evident in Urdu poetry as well. Muhammad Jaan Atif bases the foundation of his poetry upon these very sempiternal emotions. His venture is based on romance which has been presented by his own respective citation. In this article romantic elements will be developed in Muhammad Jaan Atif ode.

Keywords: Romanticism, passion, human, loved, Vrdu odes, insanity, bounteous, authenticity, sempiternal, venture.

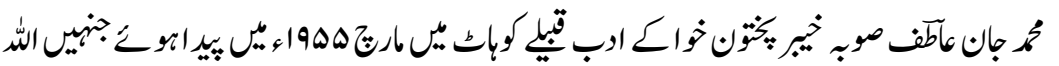

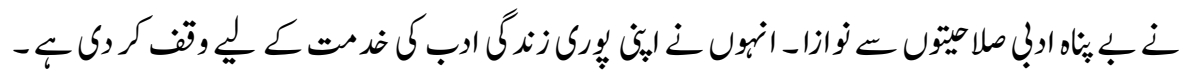

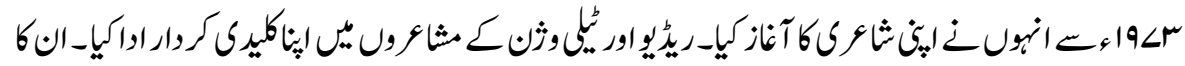

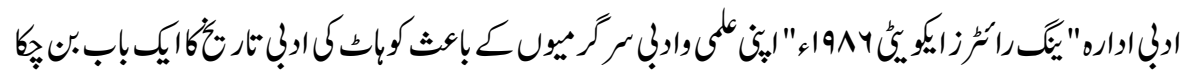

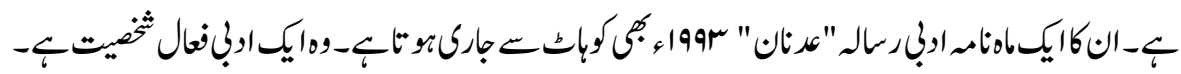

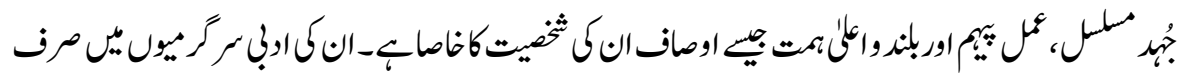

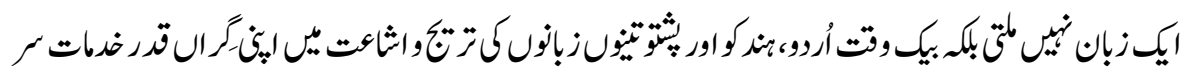

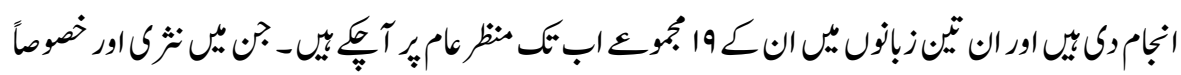

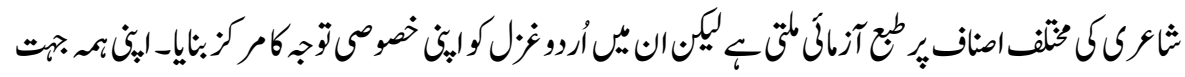




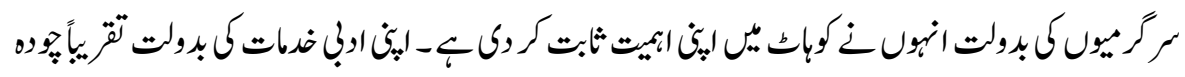

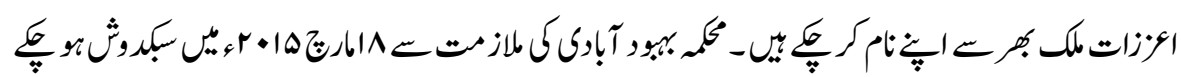

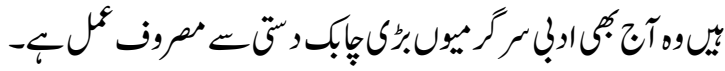

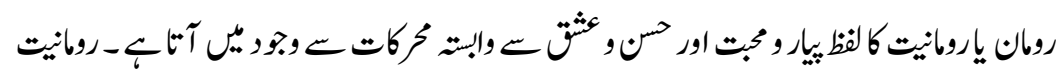

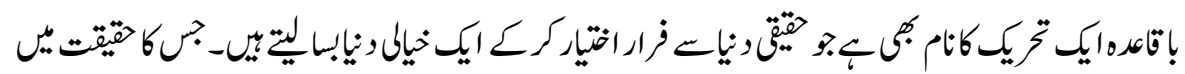

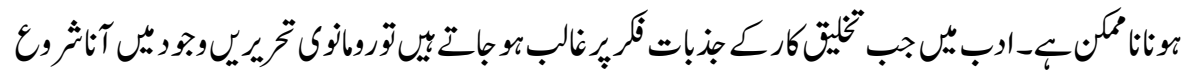
كو باقّيب-

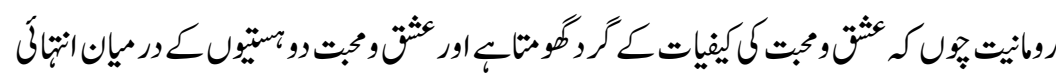

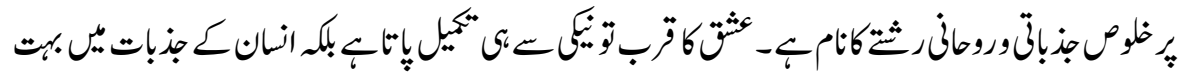

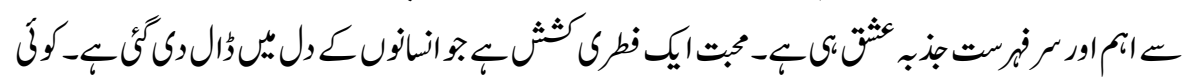

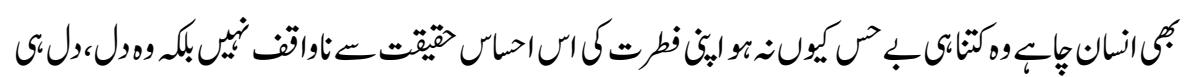

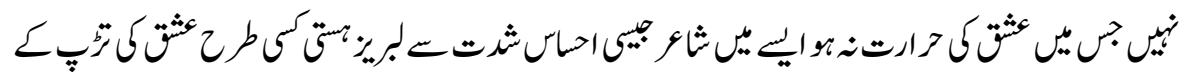

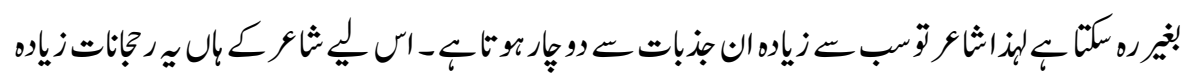
بإبخ

اس كلاوهز

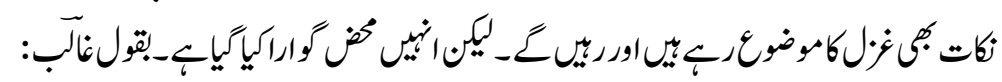
(2)

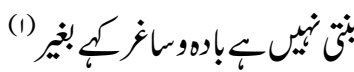

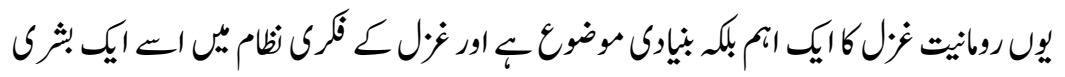

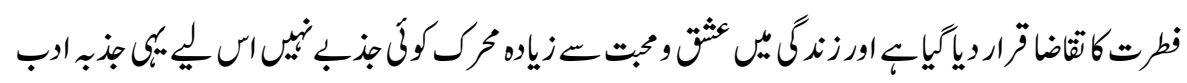

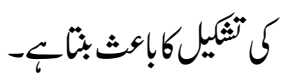

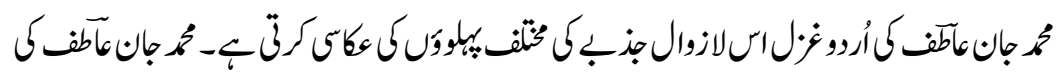

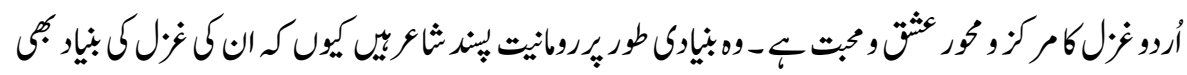




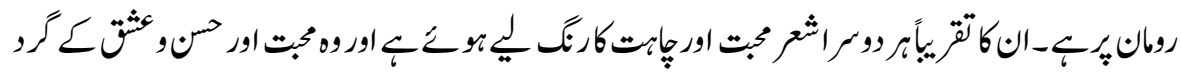

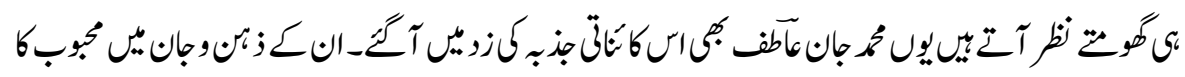

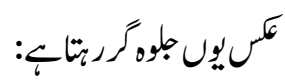

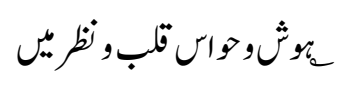

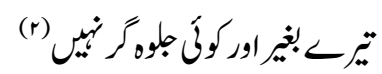

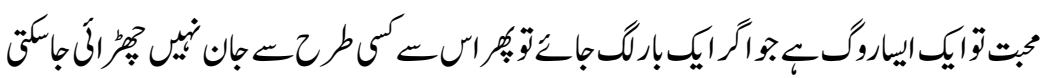

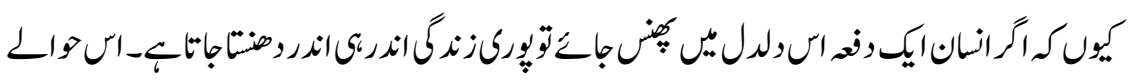

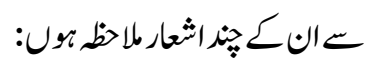

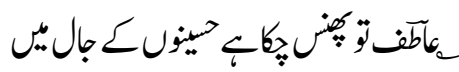

(r)

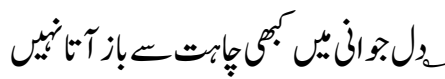

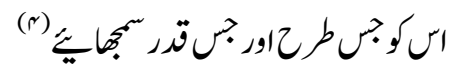
نجان

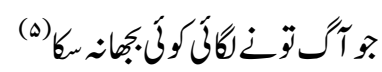

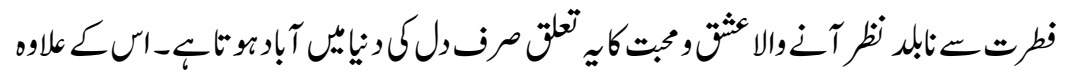

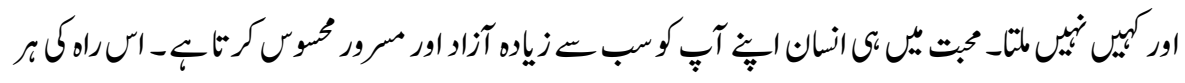

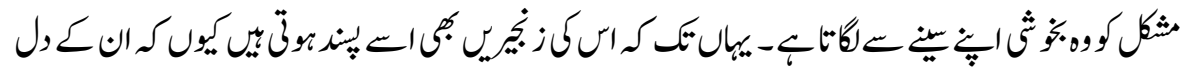

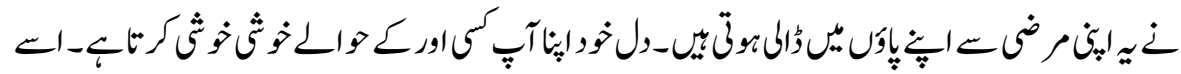

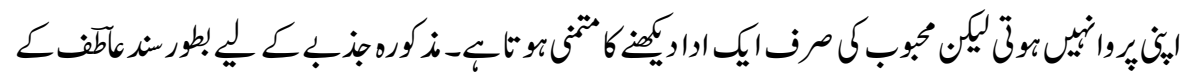

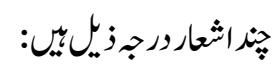

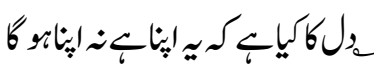

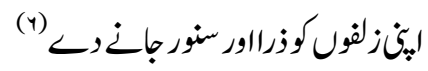

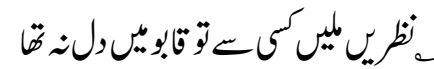


(L)

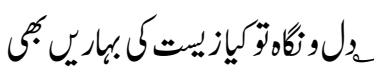

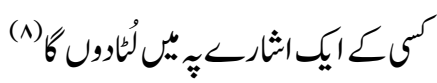

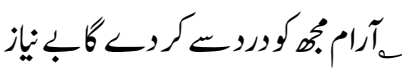

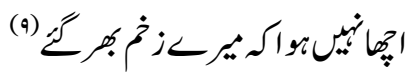

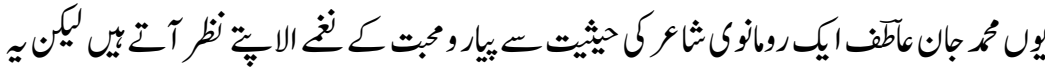

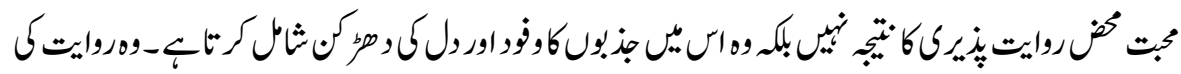

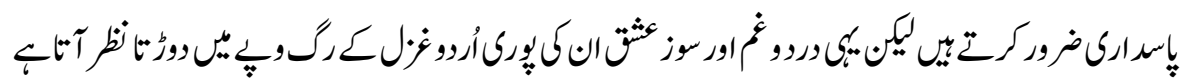

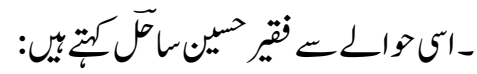

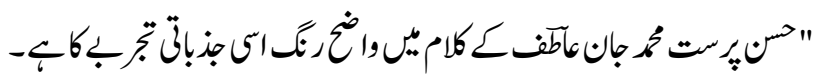

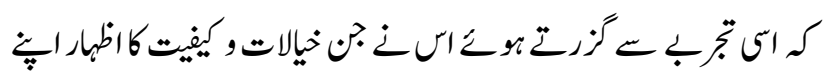

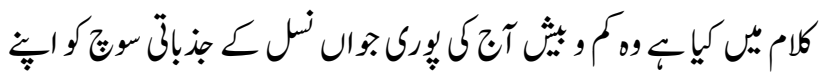

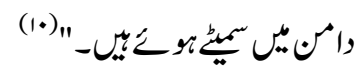

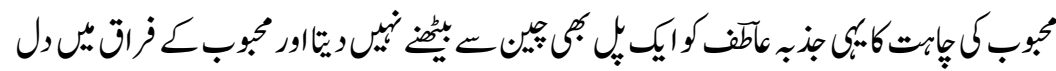

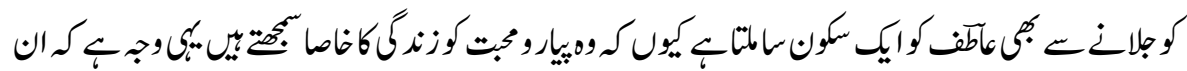

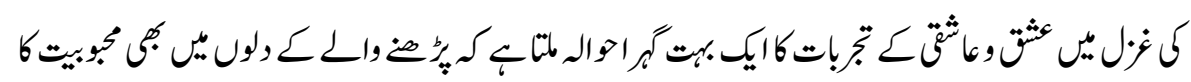

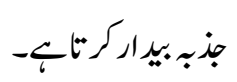

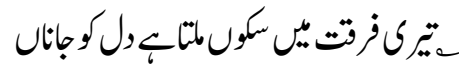

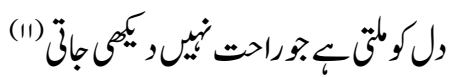

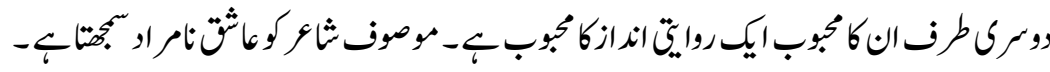

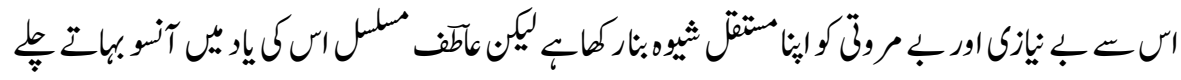

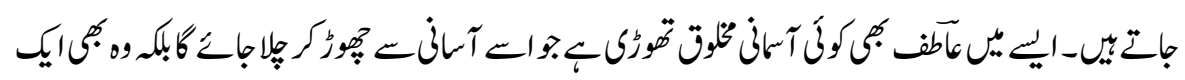

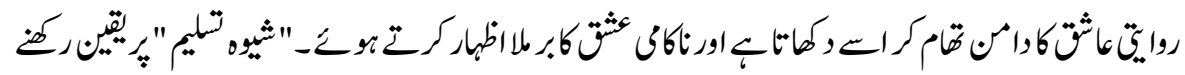




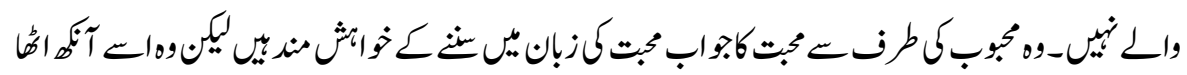

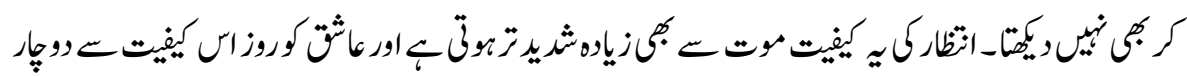

$$
\begin{aligned}
& \text { مونائر }
\end{aligned}
$$

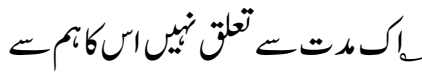

$$
\begin{aligned}
& \text { اكسدت الكيرل آبكاثيراكَ) }
\end{aligned}
$$

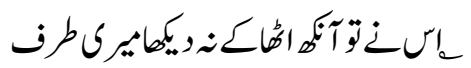

$$
\begin{aligned}
& \text { ئسن }
\end{aligned}
$$

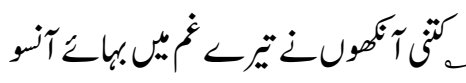

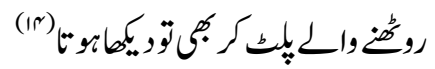

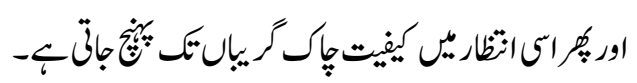

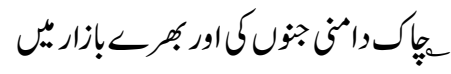

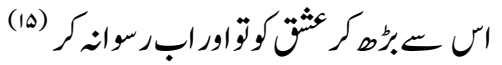

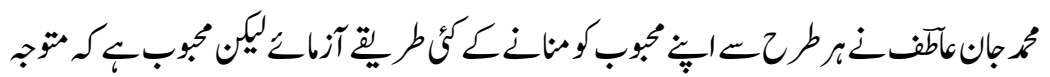

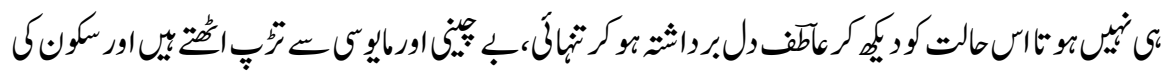

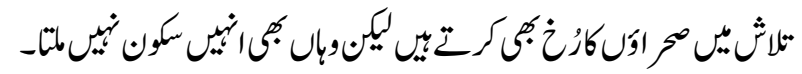

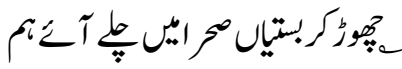

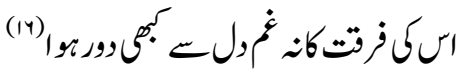

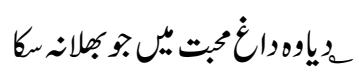

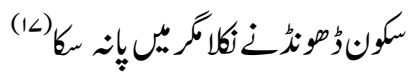

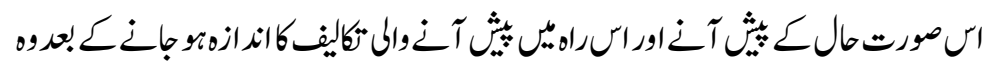

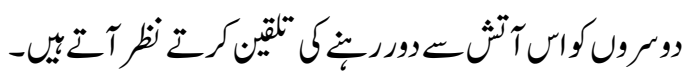

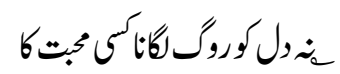

$$
\begin{aligned}
& \text { (1) }
\end{aligned}
$$




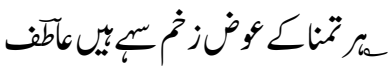

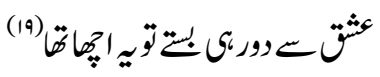

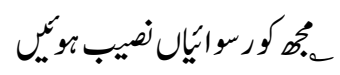

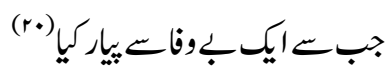

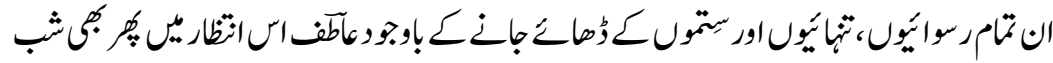

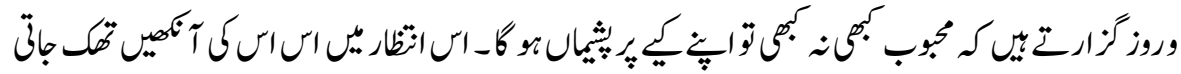

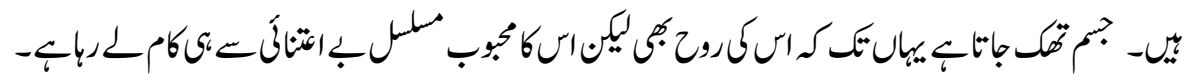

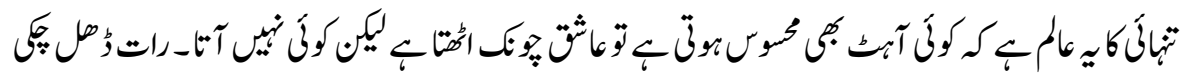

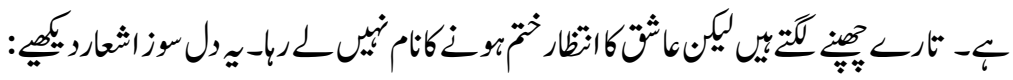

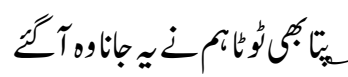

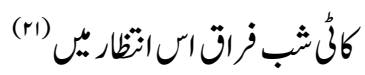
䒠 تير أنير

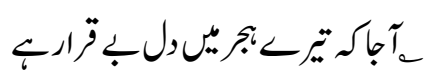

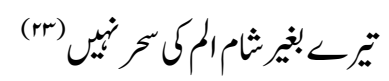

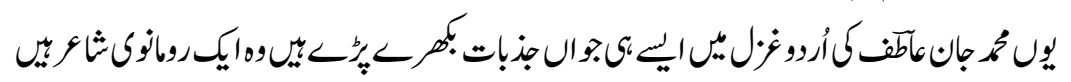

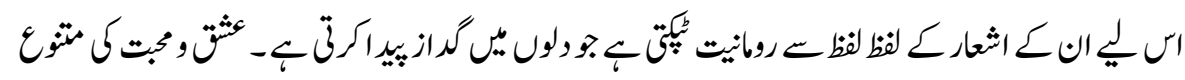

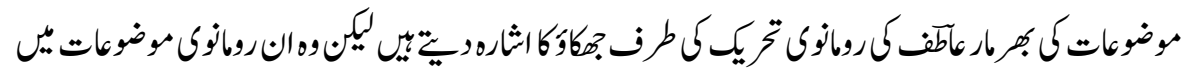

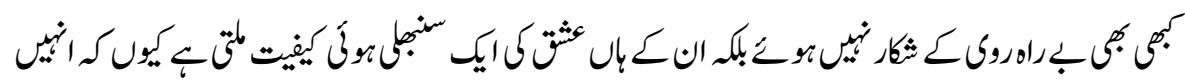

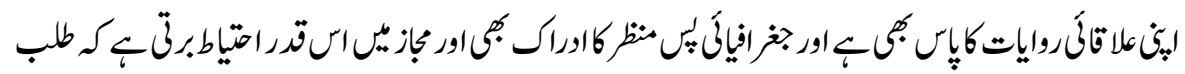

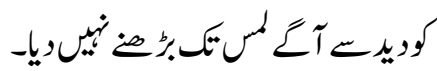

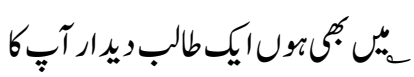

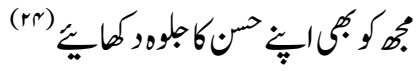




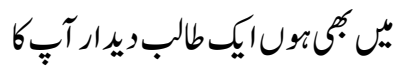

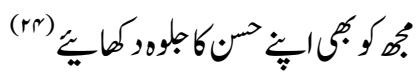

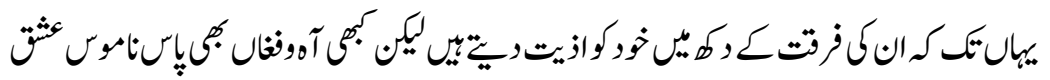

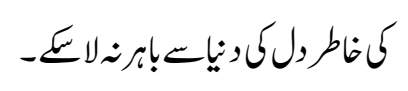

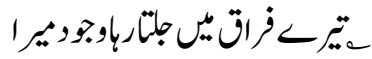

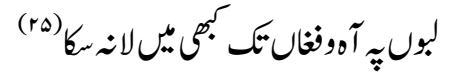

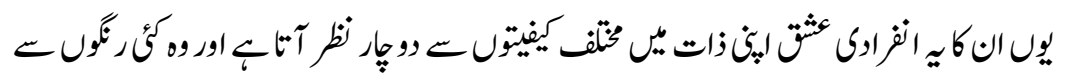

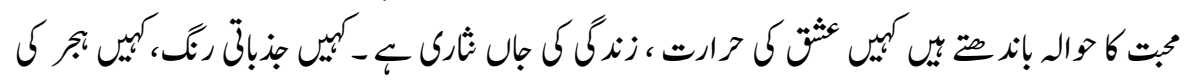

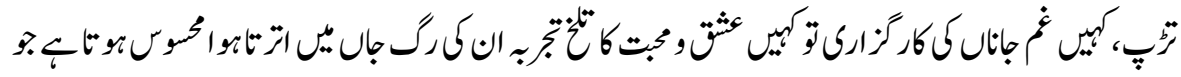

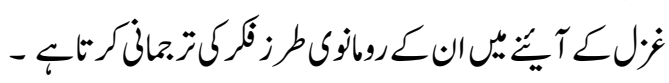

\section{حواله جإت}

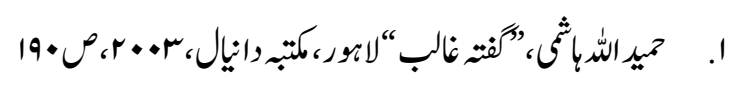
r.

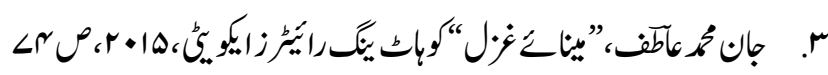

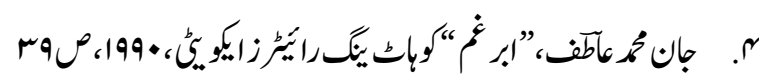

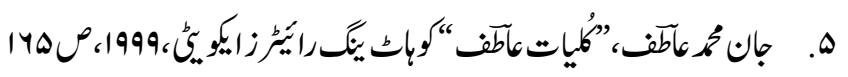

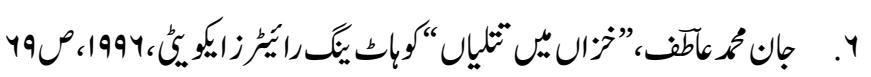

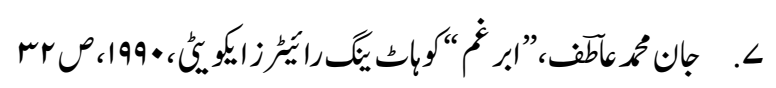

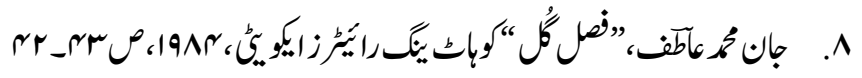
9.

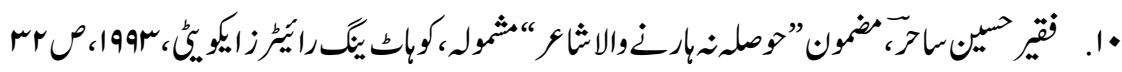

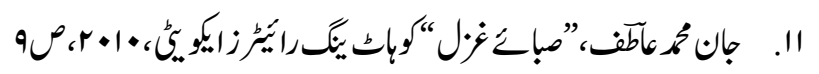




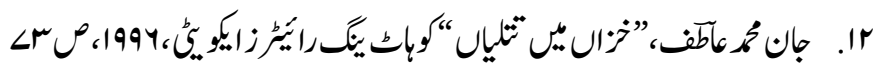

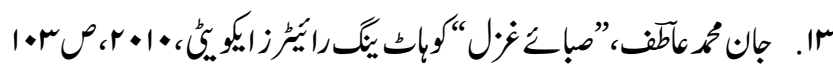
هr

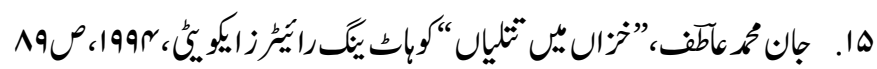

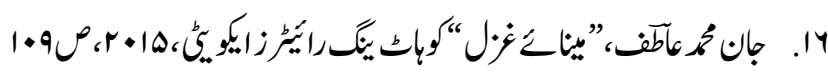
Lا. اليضأص r. r.

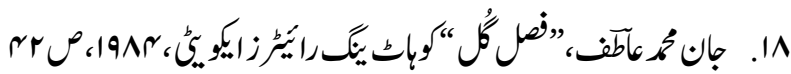
19. الينأ، صrr

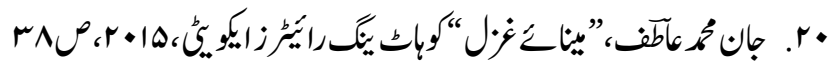

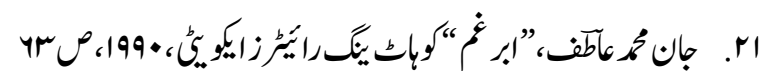

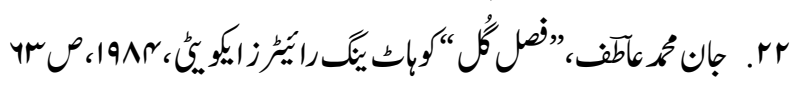
r rr. اليضاً، ص. هr. اليضاً، صاه 